\title{
Pain and dyspnea control during awake fiberoptic bronchoscopy in critically ill patients: safety and efficacy of remifentanil target-controlled infusion
}

\author{
Margot Caron ${ }^{1}$, Antoine Parrot ${ }^{1}$, Alexandre Elabbadi ${ }^{1}$, Sophie Dupeyrat ${ }^{1}$, Matthieu Turpin ${ }^{1}$, Thomas Baury ${ }^{1}$, \\ Sacha Rozencwajg ${ }^{1}$, Clarisse Blayau', Jean-Pierre Fulgencio ${ }^{1}$, Aude Gibelin' ${ }^{1}$ Pierre-Yves Blanchard ${ }^{1}$, \\ Séverine Rodriguez ${ }^{1}$, Daisy Daigné ${ }^{1}$, Marie-Cécile Allain ${ }^{1}$, Muriel Fartoukh ${ }^{1,3}$ and Tài Pham²*
}

\begin{abstract}
Purpose: Flexible fiberoptic bronchoscopy is frequently used in intensive care unit, but is a source of discomfort, dyspnea and anxiety for patients. Our objective was to assess the feasibility and tolerance of a sedation using remifentanil target-controlled infusion, to perform fiberoptic bronchoscopy in awake ICU patients.

Materials, patients and methods: This monocentric, prospective observational study was conducted in awake patients requiring fiberoptic bronchoscopy. In accordance with usual practices in our center, remifentanil targetcontrolled infusion was used under close monitoring and adapted to the patient's reactions. The primary objective was the rate of successful procedures without additional analgesia or anesthesia. The secondary objectives were clinical tolerance and the comfort of patients (graded from "very uncomfortable" to "very comfortable") and operators (numeric scale from 0 to 10) during the procedure.

Results: From May 2014 to December 2015, 72 patients were included. Most of them (69\%) were hypoxemic and admitted for acute respiratory failure. No additional medication was needed in $96 \%$ of the patients. No severe sideeffects occurred. Seventy-eight percent of patients described the procedure as "comfortable or very comfortable". Physicians rated their comfort with a median [IQR] score of 9 [8-10].
\end{abstract}

Conclusion: Remifentanil target-controlled infusion administered to perform awake fiberoptic bronchoscopy in critically ill patients is feasible without requirement of additional analgesics or sedative drugs. Clinical tolerance as well as patients' and operators' comfort were good to excellent. This technique could benefit patients' experience.

Keywords: Flexible fiberoptic bronchoscopy, Remifentanil target-controlled infusion, Intensive care unit, Tolerance, Comfort

\footnotetext{
*Correspondence: tai.pham@aphp.fr

2 Université Paris-Saclay, AP-HP, Service de médecine intensiveréanimation, Hôpital de Bicêtre, DMU CORREVE, FHU SEPSIS,Groupe de recherche clinique CARMAS, Le Kremlin-Bicêtre, France Full list of author information is available at the end of the article
}

\begin{abstract}
Background
Pain management remains a major challenge in intensive care units (ICU), and common ICU procedures, such as fiberoptic bronchoscopy (FOB) may induce important levels of pain [1-4]. The International Association for the Study of Pain has defined procedural pain as "the unpleasant sensory and emotional experience that arises from actual or potential tissue damage
\end{abstract}


associated with diagnostic or treatment procedures" [5], of which an inadequate management may have major consequences. Under-treatment of pain in postoperative period generates specific complications: sympathetic response increases levels of circulating catecholamines leading to an elevation of heart rate, blood pressure, with the risk of myocardial ischemia or bleeding [6-8]. In critically ill patients, memory of pain is a major risk of post-traumatic stress syndrome, which may be persistent and impairs patient rehabilitation and family dynamics [9]. Unrelieved ache has been identified as one of the main source of psychological stress for ICU patients [10]. Patients in the ICU often experience several procedures, or the same procedure repeated several times, such as central line or arterial catheters insertion, diagnostic or therapeutic fiberoptic bronchoscopies. Each new procedure adds anxiety to an already stressful situation [11]. Because procedural pain can be anticipated, it can also be relieved [1, 2]. Under-treated, suffering has medical consequences, but also impairs the condition under which the examinations are performed, with major risk of patients' agitation and failure of the procedure. Evaluating and treating pain is of paramount importance and is a simple means to decrease duration of mechanical ventilation and ICU length of stay by limiting the use of sedatives and neuromuscular blockers [12].

In many situations patients are unable to report or verbalize pain and discomfort due to intubation or altered consciousness [1]. Besides, variation of physiologic parameters, often used as an indicator of pain, is insufficient when used alone [13]. Behavioral response, well correlated with the intensity of procedural pain, seems to be a good option to enhance patient's assessment $[1,13$, 14]. Pain should be routinely monitored in ICU patients, and preemptive analgesia should be administered to alleviate pain before any painful action. The clinical practice guidelines for pain, agitation and delirium recommend the use of intravenous opioids in such circumstance [15].

Remifentanil is a potent, ultra-short selective $\mu$ opioid, with a short context-sensitive half-time, allowing prolonged infusion without excessive accumulation [16, 17]. It is hydrolyzed by plasmatic and tissues nonspecific esterase, and undergoes rapid metabolism, independent of renal and liver functions $[18,19]$. This organ-independent metabolism is a very interesting characteristic for intensive care patients who often present with organ dysfunctions. Remifentanil has been used with a targetcontrolled infusion (TCI) pharmacokinetic model in nonintubated critically ill patients requiring FOB with a good tolerance [20]. A recent study showed that remifentanil TCI was also effective and safe in spontaneously breathing patients with severe acute hypoxemic respiratory failure, when FOB could not be performed under single topical anesthesia [21].

We aimed at assessing the feasibility of using remifentanil TCI without adjunction of any other medication during FOB in the ICU. We also evaluated patients' tolerance as well as operators' and patients' comfort during the procedure.

\section{Materials and methods \\ Study design and population}

This is a prospective non-interventional, observational, monocentric study. All consecutive patients requiring a FOB in our ICU as per treating physician were considered for inclusion between May 2014 and December 2015. If several FOBs were performed with remifentanil TCI on a patient, only the first was considered for inclusion. Thus, to avoid any memorization bias, a patient could only be included one time. Inclusion criteria required the patients to be conscious (Richmond Agitation Sedation Score (RASS) >-3) regardless of the use of mechanical ventilation [22]. Patients younger than 18 years, pregnant or breastfeeding women, comatose patients (Glasgow score $<8$ ), with a contraindication to remifentanil, or unable to provide their consent were excluded. This study was conducted in accordance with the amended Declaration of Helsinki and was approved by the local ethics committee. All patients consented to participate.

\section{Protocol}

Remifentanil was infused with a $2 \mathrm{ng} / \mathrm{mL}$ initial brain effect-site concentration (Cet). FOB started only when this target was reached. A topical anesthesia for the nose (2\% lidocaine chlorhydrate gel), the oropharynx (5\% lidocaine chlorhydrate spray) and the tracheobronchial tree $(1 \%$ lidocaine chlorhydrate, $5 \mathrm{~mL}$ ) was used as per department's protocol.

Remifentanil target-controlled infusion (Base Primea, Fresenius ${ }^{\circledR} \mathrm{Kabi}$, Minto model) was then titrated by $0.5 \mathrm{ng} / \mathrm{mL}$ steps according to patient's reactions with a maximum of $6 \mathrm{ng} / \mathrm{mL}$ of brain Cet. The procedure started when adequate sedation (Observer Assessment of Alertness and Sedation scale (OAA/S) score 2-3) was reached [23]. Potential side effect managements were protocolized and are specified in the Additional file 1. In case of patient discomfort or agitation, $0.25 \mathrm{mg} / \mathrm{kg}$ of propofol could be infused to allow achievement of the procedure in optimal conditions.

Clinical data were collected every 2 min during the procedure (respiratory rate, oxygen saturation, heart rate and blood pressure) and patient's comfort was evaluated with three hetero-assessment scales: the Puchner scale [24], cough scale, and OAA/S scale (Table 1). Total 
Table 1 Scores used for comfort, cough and sedation (by OAA/S and RASS scores)

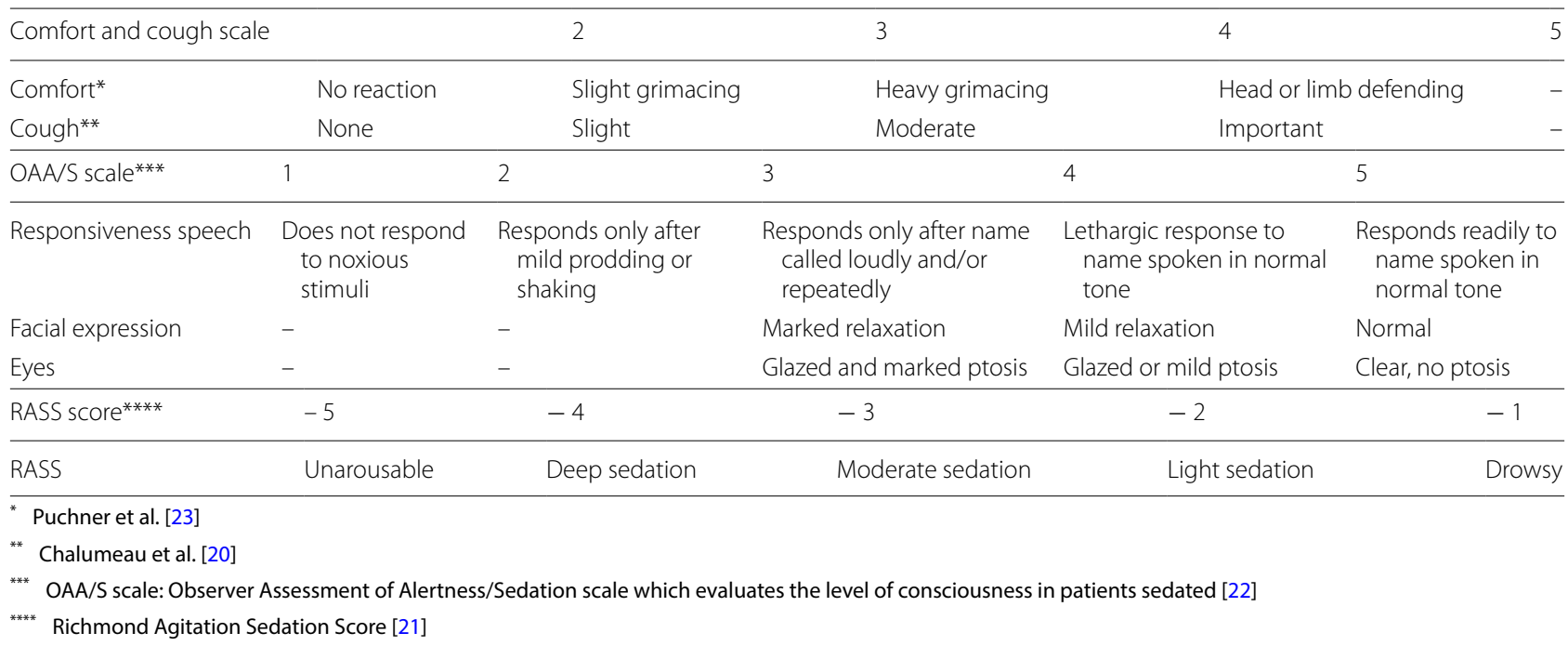

dose of remifentanil, maximal Cet and infusion duration were collected at the end of the procedure. Respiratory parameters were reassessed $1 \mathrm{~h}$ and $24 \mathrm{~h}$ after the end of the procedure. We defined intensification of ventilatory support as an increase in the need of oxygen, or a rise in the level of respiratory care from oxygen therapy to noninvasive (NIV) or invasive ventilation in previously spontaneous breathing patients.

The operator rated his/her comfort in performing the procedure on a numeric scale going from 0 ("very uncomfortable conditions") to 10 ("maximal comfort") after the end of the FOB.

To avoid any judgement alteration due to residual effect of the drugs, patients' experience assessment was performed $24 \mathrm{~h}$ after the procedure: pain and comfort were assessed with numeric scales going from 0 to 10 . Tolerance, memorization and theoretical approval for repetition of the same procedure in similar conditions were assessed [25].

\section{Outcomes}

The main outcome was the rate of procedure success defined as the achievement of the FOB with remifentanil TCI alone and no requirement for additional sedative drug.

The secondary objectives were the clinical tolerance of the FOB and sedation, in particular respiratory tolerance evaluated by the intensification of ventilatory support after the procedure, and the patient's and the operator's comfort during the procedure.

\section{Statistics}

Continuous variables are reported as means $\pm S D$ or median (first, third quartiles), and categorical variables as count and proportion. Normality of the data distribution was visually assessed by means of histograms. Comparisons of proportions were made using Chi-square and Fisher exact tests. Continuous variables were compared using Student's $t$ tests or Wilcoxon rank sum test statistics. Numeric variables at two different time points were compared with paired t-test or Wilcoxon test. No assumptions were made for missing data, and we followed the Strengthening the Reporting of Observational Studies in Epidemiology (STROBE) recommendations [26]. Statistical analyses were done with $\mathrm{R}$ (version 3.5.1, http://cran.r-project.org). All P values were two-sided, and value less than 0.05 was considered statistically significant.

\section{Results}

Between May 2014 and December 2015, 72 patients requiring a FOB were included. Forty percent were men, with a mean age of $57 \pm 17$ years and a mean Simplified Acute Physiological Score (SAPS2) of $33 \pm 16$. Main reasons for ICU admission were respiratory failure (69\%), thoracic trauma or surgery (21\%). Most patients were hypoxemic: $46 \%$ needed more than $8 \mathrm{~L} / \mathrm{min}$ of oxygen, $21 \%$ received high-flow humidified oxygen therapy through nasal cannula (HFNC), 10\% were treated with NIV. None required vasoactive drugs at the moment when the procedure was performed. Patients' baseline characteristics are shown in Table 2.

A total of 72 procedures were assessed in 72 different patients. A concomitant broncho-alveolar lavage 
Table 2 Demographic and baseline characteristics

\begin{tabular}{|c|c|}
\hline Age, mean $\pm S D$, years & $57.4 \pm 17.4$ \\
\hline Male, $n(\%)$ & $29(40)$ \\
\hline $\mathrm{BMl}$, mean $\pm \mathrm{SD}, \mathrm{kg} / \mathrm{m}^{2}$ & $25 \pm 6$ \\
\hline SAPS2, mean \pm SD & $33 \pm 16$ \\
\hline \multicolumn{2}{|l|}{ Comorbidities, $n(\%)$} \\
\hline Active smoking & $35(49)$ \\
\hline COPD & $23(32)$ \\
\hline Other pulmonary disease & $13(18)$ \\
\hline Chronic heart disease & $4(6)$ \\
\hline Immunosuppression & $30(42)$ \\
\hline \multicolumn{2}{|l|}{ Main cause of ICU admission, $n(\%)$} \\
\hline Respiratory failure & $34(48)$ \\
\hline Pneumonia & $20(28)$ \\
\hline Acute interstitial pneumonia & $7(10)$ \\
\hline Acute chest syndrome & $4(6)$ \\
\hline Other & $3(4)$ \\
\hline Hemoptysis & $19(26)$ \\
\hline Thoracic surgery/traumatism & $11(15)$ \\
\hline Abdominal surgery & $1(1)$ \\
\hline Extra-pulmonary sepsis & $2(3)$ \\
\hline Other & $5(7)$ \\
\hline \multicolumn{2}{|c|}{ Pre-bronchoscopic respiratory parameters } \\
\hline $\mathrm{SpO}_{2}$, median [IQR], \% & 97 [94.8-99.2] \\
\hline$R R$, mean $\pm S D$, per min & $27 \pm 9$ \\
\hline $\mathrm{PaO}_{2}<60 \mathrm{mmHg}, n(\%)$ & $17(24)$ \\
\hline RR > 30 cycles per min, $n(\%)$ & $34(47)$ \\
\hline \multicolumn{2}{|l|}{ Respiratory support, $n$ (\%) } \\
\hline Oxygen therapy $>8 \mathrm{~L} / \mathrm{min}$ & $30(42)$ \\
\hline HFNC & $15(21)$ \\
\hline NIV & $7(10)$ \\
\hline Invasive mechanical ventilation & $4(6)$ \\
\hline \multicolumn{2}{|c|}{ Pre-bronchoscopic hemodynamic parameters } \\
\hline MAP, median [IQR], mmHg & $93[83-101]$ \\
\hline $\mathrm{HR}$, mean $\pm S D$, beat per min & $99 \pm 21$ \\
\hline
\end{tabular}

BMI: body mass index, SAPS2: Simplified Acute Physiologic Score, COPD: chronic obstructive pulmonary disease, $\mathrm{SpO}_{2}$ : oxygen saturation by pulse oximetry, RR: respiratory rate, $\mathrm{PO}_{2}$ : arterial partial pressure of oxygen, $\mathrm{HFNC}$ : high-flow humidified oxygen therapy through nasal cannula, NIV: non-invasive ventilation, MAP: mean arterial pressure, HR: heart rate

(BAL) or bronchial biopsies were performed in $22 \%$ and $4.2 \%$ of them, respectively. The main indications for FOB were worsening of respiratory failure, etiological diagnosis inquiry or hemoptysis $(n=29,22$ and 18 , respectively). Four procedures (6\%) were performed in intubated patients. The median [IQR] duration of remifentanil infusion was 22 [15-28] min for a median procedure duration of 11 [8-19] min. The total dose of remifentanil was 252 [164-343] $\mu \mathrm{g}$, with a mean maximal Cet of $4.4 \pm 1.2 \mathrm{ng} / \mathrm{mL}$.
Sixty-nine procedures (96\%) were successfully performed without any additional sedative drug requirement (primary outcome). No severe adverse event occurred, and no reversal agent was ever used (naloxone). Physiological parameters are showed in Table 3.

Oxygen levels were increased for the procedure in patients treated with standard oxygen therapy $(6[4 ; 9]$ vs. $4[2 ; 6] \mathrm{L} / \mathrm{min}, p=0.013$ ) as well as $\mathrm{FiO}_{2}$ in patients receiving NIV, HFNC or invasive mechanical ventilation (1 $[0.60 ; 1]$ vs. $0.6[0.4 ; 1], p=0.008)$.

The minimal per-procedure oxygen saturation was significantly lower than that at baseline (94\% [92-97] vs. 97\% [94-99], $p<0.001)$, but $\mathrm{SpO}_{2} 1 \mathrm{~h}$ after the procedure did not differ from baseline $\mathrm{SpO}_{2}(p=0.244)$.

All but one patient had the same type of ventilation support before and during the procedure. This patient was treated with $12 \mathrm{~L} / \mathrm{min}$ oxygen through nonrebreather mask before the procedure, and treatment was increased to high-flow humidified oxygen therapy through nasal cannula to secure the procedure.

The ventilatory support was increased in $13(18 \%)$ patients within $24 \mathrm{~h}$ after the procedure, most of them for worsening hypoxemia $(n=10$; one patient required invasive mechanical ventilation, another needed NIV, the remaining 8 patients required higher oxygen levels). Three other patients required invasive mechanical ventilation for emergent surgery unrelated to the FOB procedure. Conversely, 41 patients (57\%) needed less oxygen within $24 \mathrm{~h}$ after the procedure. There was no difference of remifentanil dose administered between the 13 patients who presented respiratory failure worsening and the 59 other patients $(264[147-384]$ vs 249 [169-348] $\mu \mathrm{g}, p=0.838$ ).

During the FOB, $30.6 \%$ of the patients presented no cough, $59.7 \%$ a moderate cough, and $9.7 \%$ an important cough. The evaluation by Puchner score was performed in 55 patients, among whom $51 \%$ showed no reaction. Slight grimaces, heavy grimacing, and agitation were noticed in $29.1 \%, 10.9 \%$ and $1.8 \%$ of patients, respectively (Fig. 1).

Subjective perception of the procedure was assessed at $24 \mathrm{~h}$ in 50 patients $(69.4 \%)$. The great majority of them (98\%) could remember at least a part of the procedure, $78 \%$ felt "comfortable" or "very comfortable", 96\% suffered "no pain" or a "moderate pain" and $85.4 \%$ declared they would accept to repeat the procedure under the same conditions if needed (Table 4). Fifty-one percent of the physicians reported on their comfort performing the procedure and the median [IQR] score was 9 [8-10]. 
Table 3 Physiological parameters at baseline, during the procedure and after $1 \mathrm{~h}$ (median [IQR])

\begin{tabular}{|c|c|c|c|c|}
\hline & Baseline & Minimal per-procedure & Maximal per-procedure & After $1 \mathrm{~h}$ \\
\hline $\mathrm{SpO}_{2}(\%)$ & 97 [94-99] & $94[92-97]^{*}$ & $99[97-100]^{*}$ & $\begin{array}{l}97[95-99] \\
p=0.244\end{array}$ \\
\hline RR (cycles/min) & $27[20-31]$ & $18[12-22]^{*}$ & $30[24-36]^{*}$ & $\begin{array}{l}23[20-28] \\
p=0.004\end{array}$ \\
\hline HR (beats/min) & $100[83-111]$ & $95[77-107]^{*}$ & $106[93-124]^{*}$ & $\begin{array}{l}94[83-106] \\
p=0.026\end{array}$ \\
\hline SAP $(\mathrm{mmHg})$ & 139 [118-149] & $126[110-137]^{*}$ & $151[139-168]^{*}$ & $\begin{array}{l}130[118-137] \\
p=0.052\end{array}$ \\
\hline MAP $(\mathrm{mmHg})$ & 93 [83-101] & $87[80-95]^{*}$ & $104[93-113]^{*}$ & $89[81-98]^{*}$ \\
\hline
\end{tabular}

$\mathrm{SpO}_{2}$ : oxygen saturation by pulse oximetry, RR: respiratory rate, HR: heart rate, SAP: systolic arterial pressure, MAP: mean arterial pressure. Parameters compared with baseline with paired Wilcoxon test

${ }^{*} p<0.001$

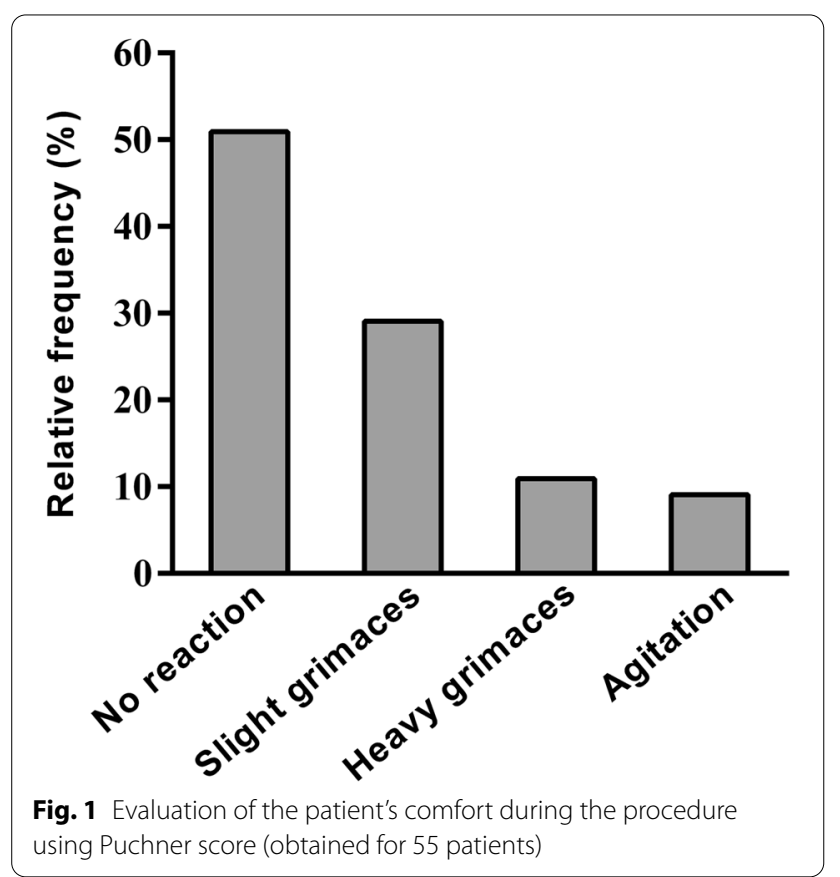

\section{Discussion}

This study showed that the use of remifentanil TCI for FOB was feasible, safe and enabled comfortable examination settings for the patients as well as for the physicians in charge of the procedure. This analgesic protocol was well tolerated despite being performed in ICU patients with respiratory failure.

Patients developed a transient and reversible desaturation and physicians increased the levels of oxygen or $\mathrm{FiO}_{2}$ for the procedure, likely anticipating procedure induced hypoxemia expected in this fragile patient population. Only one patient had a change of oxygen delivery device for the procedure, escalating from non-rebreather mask (12L/min) to HFNC. In this patient, the broncho-alveolar
Table 4 Evaluation of patient's comfort and perceptions (assessed in 50 patients). Results are presented as $n$ (\%)

\begin{tabular}{lc}
\hline Memory, $n$ (\%)* & \\
I remember everything & $27(55.1)$ \\
I remember the most part of the procedure & $14(28.6)$ \\
I remember few things & $7(14.3)$ \\
I don't remember anything & $1(2.0)$ \\
Comfort: "During the procedure, I felt...," $n$ (\%) & \\
Very comfortable & $9(18.0)$ \\
Comfortable & $30(60.0)$ \\
Uncomfortable & $8(16.0)$ \\
Very uncomfortable & $2(4.0)$ \\
I can't tell & $1(2.0)$ \\
Pain: "During the procedure, I had...," $n$ (\%) & \\
No pain & $32(64.0)$ \\
Moderate/bearable pain & $16(32.0)$ \\
Unbearable pain & $1(2.0)$ \\
I can't tell & $1(2.0)$ \\
Tolerance: "I would agree to to undergo the same procedure in & \\
the same conditions," $n$ (\%)** & \\
Certainly yes & $20(41.7)$ \\
Likely yes & $21(43.8)$ \\
Likely not & $5(10.4)$ \\
Certainly not & $1(2.1)$ \\
I can't tell & $1(2.1)$
\end{tabular}

The patients were asked about their perceptions $24 \mathrm{~h}$ after the procedure

* Assessed in 49 patients

** Assessed in 48 patients

lavage allowed diagnosis of pneumocystis pneumonia and in this context, the increment of ventilation support would have occurred with or without the procedure. FOB may lead to transient hypoventilation and drop of oxygenation [27], especially during BAL. In a prospective multicenter study, bronchoscopy performed in critically 
ill hypoxemic patients was associated with an increase in ventilatory support [28]; immunosuppression and COPD were associated with the need for intubation within the $24 \mathrm{~h}$ after the procedure. In our study, patients with immunosuppression and COPD represented, respectively, $42 \%$ and $32 \%$ of the population. However, only one of them was intubated after the FOB for an emergent surgery which was unrelated to the procedure. In this population, FOB was indicated to diagnose or treat pulmonary conditions likely influencing the levels of oxygenation and some patients' respiratory conditions may have declined due to the natural course of their underlying disease or condition (pneumonia, hemoptysis, thoracic surgery).

None of the usual complications of opioids such as severe bradypnea, thoracic rigidity or significative bradycardia occurred, and no reversal agent was needed in our study [29-33]. It is comforting that these most feared complications did not happen in a population of 72 hypoxemic patients. As remifentanil is a very potent and short-acting opioid, we assume that TCI administration allowing a quick equilibration of plasmatic and tissues' concentrations is a safe way of delivering this drug. Recently, Rezaiguia et al. performed FOB under remifentanil TCI sedation in a series on 39 hypoxemic patients. The authors reported an increase in ventilatory support after the procedure in $23 \%$ of them [21]. Noteworthy, all these patients had a recent thoracic surgery and a previous failure of FOB under topical anesthesia because of discomfort, agitation or respiratory failure. In a multicenter cohort of 169 spontaneous breathing ICU patients with acute respiratory failure and no information regarding the sedation use, $35 \%$ of the awake FOB leaded to an increase in ventilatory support [28]. In our study, better tolerance of the procedure and the lower rate of ventilatory support increase could be explained by the pharmacological effects of remifentanil and its delivery by a TCI syringe, thus allowing precise titration, personalized treatment, and preventing side-effects as well as insufficient sedation.

Patients whose experience was assessed mainly rated it as "comfortable" or "very comfortable". This was consistent with physicians' perceptions who mostly appreciated examination conditions. Therefore, our results, suggest that we may improve patient's experience and operator's comfort without increasing the risk of the complications.

Awake FOB is known to be unpleasant and an important source of pain and anxiety [3, 4, 34]. Respiratory tract stimulation causes cough leading to patient's discomfort and technical challenge for the physician.

Moreover, FOB can cause dyspnea and desaturation in patients who are already at risk due to their underlying pathology. Studies comparing remifentanil TCI with propofol TCI found that intubation conditions as well as patient comfort were better with remifentanil [35, 36]. Remifentanil might be an appropriate drug for respiratory tract procedures because it modulates the perception of dyspnea [37-39], but also due to its strong analgesic properties [16, 17]. FOB is painful and other drugs usually administered for this procedure do not have such analgesics power [40-42]. Remifentanil provides a better satisfaction than a procedure without any sedation and is efficient on different components of suffering: pain, dyspnea and anxiety. Morphine and midazolam titrations are easy to implement, but both have longer onsets and offsets making them less adjustable. Ryu et al. compared a vigil sedation with propofol-dexmedetomidine, and propofol-remifentanil to perform vigil FOB [43]. In the dexmedetomidine group, patients experienced fewer transient desaturations, but they also reported less comfort and satisfaction. In 2011, Clouzeau et al. performed BAL under awake sedation with propofol in 23 patients with acute respiratory failure under NIV. Respiratory status one hour after the procedure was not different from baseline. Three patients (17\%) were intubated $24 \mathrm{~h}$ after the procedure and mean arterial pressure was transiently lower under sedation, but stayed in acceptable levels [44]. As opposed to our study, all procedures were performed under NIV which was maintained for at least $1 \mathrm{~h}$ after FOB and authors used propofol. Propofol used for vigil FOB in a small series of 18 patients with pneumonia showed improved patient satisfaction, with reduced cough, pain and sensation of asphyxiation as compared to procedure without sedation [25]. Propofol and remifentanil are both suitable molecules for the sedation of short procedures as both have the rapid onset/short-acting effect and both have good results on the control of procedural pain. However, propofol induces more amnesia, which comes with hemodynamic repercussions by sympatholysis and has a larger impact on the oropharyngeal tonus with an increased risk of obstructive apnea [35]. These expected side-effects can be partially avoided by a close management of its administration, or a combined sedation, for example with ketamine [45].

Alleviating acute, chronic or procedural dyspnea, considered as unpleasant and harmful as pain, should be a daily goal for the physicians [46]. Though little has been reported on the painfulness of FOB, it is undoubtedly an unpleasant procedure [4, 47], particularly in patients from this cohort who suffered from independent sources of anxiety such as dyspnea or hemoptysis. Considering the negative impact of stress on the perception of pain [6-10,48], assessing and relieving patients' stress and pain levels becomes a priority. Hence, current guidelines already recommend the use of sedation to perform this procedure [49]. 
Several studies have also demonstrated the benefit of a conscious sedation in ambulatory patients $[40,50]$. Improving patient's and physician's comfort during the procedure also seems to be important in critically ill hypoxemic patients.

We chose remifentanil for its appropriate pharmacological properties combining rapid onset, easy adjustment and short acting. Patients required high levels of Cet (in the range of those needed for a surgical incision) to control pain and discomfort and this is consistent with a recent study on FOB in ICU patients suffering from acute respiratory distress syndrome in which Cet exceeded $4 \mathrm{ng} / \mathrm{mL}$ [21]. Several hypotheses could explain this phenomenon. First, the procedural pain might have been underestimated. The need for high levels of Cet could reflect higher levels of suffering during the procedure, and could also translate the impact of baseline pain on procedural pain (i.e., greater suffering in ICU patients due to a higher baseline) [1]. Second, Cet was adapted depending on patient's reactions, cough, movements and grimaces, as in most cases patients could not talk during the procedure. Thus, we could have incremented remifentanil doses to inhibit cough reflex during the procedure, without consequences as no severe complications and no signs of overdose occurred. No perfect tool exists, and hetero-assessment is a difficult task. In this study, we combined different auto- and hetero-assessment questionnaires answered at different times to limit the risk of judgment error.

Our study's main limitation is the monocentric and non-controlled design. Still, remifentanil TCI for fiberoptic bronchoscopy remains relevant even for center with no or limited exposure to this technique: when it was implemented in 2012, only one physician was familiar to this technique and introduced it to the rest of the team. The whole team including most physicians with a respirologist background (used to perform this procedure with topical anesthesia for decades) quickly adopted remifentanil TCI sedation and became routine standard of care in our center. We thus considered not ethical to select a control group not receiving optimal pain medication.

In comparison with other ICU cohorts, our population had a stable hemodynamic status and did not require vasoactive agents. We did not show significant variations in hemodynamics status, but it may be interesting to test the same procedure on hemodynamically unstable patients. However, as remifentanil has been shown to be well tolerated in previous studies, we expect similar results.

Assessments of perceptions about the procedure were not completed for all patients and physicians. Two-thirds of the patients were asked about their comfort after $24 \mathrm{~h}$, and half of the physicians assessed their conditions of examination. We think this is missing data at random due to organizational setting (missed 24-h follow-up time when it happened during weekends or after a staff change), and there was no specific difference between patients that were assessed and the others.

Finally, in the future, we should consider a longer follow-up to evaluate the impact of our pain management protocol on patients' feelings after ICU and hospital discharge. The promising results of this study should be integrated in a global approach of patients' comfort in ICU.

\section{Conclusion}

Remifentanil TCI is feasible and safe to provide comfort for patients requiring awake flexible fiberoptic bronchoscopy in the ICU. This is a readily available tool that could appropriately alleviate procedural pain and improve the patient's experience as well as the operator's comfort.

\begin{abstract}
Abbreviations
BAL: Broncho-alveolar lavage; BMI: Body mass index; Cet: Brain effect-site concentration; COPD: Chronic obstructive pulmonary disease; FOB: Fiberoptic bronchoscopy; HFNC: High-flow humidified oxygen therapy through nasal cannula; HR: Heart rate; ICU: Intensive care unit; MAP: Mean arterial pressure; NIV: Non-invasive ventilation; OAA/S: Observer Assessment of Alertness and Sedation scale; $\mathrm{PO}_{2}$ : Arterial partial pressure of oxygen; RASS: Richmond Agitation Sedation Score; RR: Respiratory rate; SAP: Systolic arterial pressure; SAPS2: Simplified Acute Physiological Score; $\mathrm{SpO}_{2}$ : Oxygen saturation by pulse oximetry; TCl: Target-controlled infusion.
\end{abstract}

\section{Supplementary Information}

The online version contains supplementary material available at https://doi. org/10.1186/s13613-021-00832-6.

Additional file 1. Management protocols for procedural and sedation complications.

Acknowledgements

We are grateful to Jeanne Caron Guyon for her constructive suggestions and corrections to improve this manuscript.

\section{Authors' contributions}

MC, AP, MF and TP had full access to all of the data in the study and take responsibility for the integrity of the data and the accuracy of the data analysis. TP, AP and MF contributed to study concept and design. MC, AP, AE, SD, MT $\mathrm{TB}, \mathrm{SR}, \mathrm{CB}, \mathrm{JPF}, \mathrm{AG}, \mathrm{PYB}, \mathrm{SR}, \mathrm{DD}, \mathrm{MCA}, \mathrm{MF}$ and TP helped in acquisition of data. $T P$ and $M C$ analyzed and interpreted the data and made the statistical analysis. MC and TP drafted the manuscript. MC, TP, AP, SR and MF critically revised the manuscript for important intellectual content. All authors read and approved the final manuscript.

\section{Funding}

The authors have no funding for the research to declare.

\section{Availability of data and materials}

The dataset used and analyzed during the current study are available from the corresponding author on reasonable request. 


\section{Declarations}

\section{Ethic approval and consent to participate}

This study was conducted in accordance with the amended Declaration of Helsinki and was approved by the local ethics committee (Comité de protection des personnes, lle de France V, Project number 14983, 2014). All patients consented to participate.

\section{Consent for publication}

Not applicable.

\section{Competing interests}

The authors declare that they have no competing interests to declare.

\section{Author details}

${ }^{1}$ Sorbonne Université, Assistance Publique - Hôpitaux de Paris, Service de médecine intensive réanimation, Hôpital Tenon, Paris, France. ${ }^{2}$ Université Paris-Saclay, AP-HP, Service de médecine intensive-réanimation, Hôpital de Bicêtre, DMU CORREVE, FHU SEPSIS, Groupe de recherche clinique CARMAS, Le Kremlin-Bicêtre, France. ${ }^{3}$ Groupe de Recherche Clinique GRC05 CARMAS, Institut Mondor de recherchebiomédicale, INSERM, Créteil, France.

Received: 25 September 2020 Accepted: 2 March 2021

Published online: 16 March 2021

\section{References}

1. Puntillo KA, Morris AB, Thompson CL, Stanik-Hutt J, White CA, Wild LR. Pain behaviors observed during six common procedures: results from Thunder Project II*: Critical Care Medicine. 2004;32:421-7.

2. Puntillo KA, Max A, Timsit J-F, Vignoud L, Chanques G, Robleda G, et al. Determinants of procedural pain intensity in the intensive care unit: the Europain study. Am J Respir Crit Care Med. 2014;89(1):39-47.

3. Barlési F, Dissard-Barriol E, Gimenez C, Doddoli C, Greillier L. Kleisbauer J-P. Tolerance of fiberoptic bronchoscopy by self-administered questionnaire: in the words of the patients. Rev Mal Respir. 2003;20:335-40.

4. Diette GB, White P, Terry P, Jenckes M, Wise RA, Rubin HR. Quality assessment through patient self-report of symptoms prefiberoptic and postfiberoptic bronchoscopy. Chest. 1998;114:1446-53.

5. Merskey H. Pain terms: a list with definitions and notes on usage. Recommended by the IASP Subcommittee on Taxonomy. Pain. 1979;6:249.

6. Huskisson EC. Catecholamine excretion and pain. Br J Clin Pharmacol. 1974;1:80-2.

7. Jänig W. Autonomic reactions in pain. Pain. 2012;153:733-5.

8. Beattie WS, Badner NH, Choi P. Epidural analgesia reduces postoperative myocardial infarction: a meta-analysis. Anesth Analg. 2001;93:853-8.

9. Davidson JE, Harvey MA, Bemis-Dougherty A, Smith JM, Hopkins RO. Implementation of the pain, agitation, and delirium clinical practice guidelines and promoting patient mobility to prevent post-intensive care syndrome. Crit Care Med. 2013;41:S136-45.

10. Myhren H, Ekeberg O, Toien K, Karlsson S, Stokland O. Posttraumatic stress, anxiety and depression symptoms in patients during the first year post intensive care unit discharge. Crit Care. 2010;14:R14.

11. Novaes MA, Knobel E, Bork AM, Pavão OF, Nogueira-Martins LA, Ferraz MB. Stressors in ICU: perception of the patient, relatives and health care team. Intensive Care Med. 1999;25:1421-6.

12. Payen J-F, Bosson J-L, Chanques G, Mantz J, Labarere J. Pain assessment is associated with decreased duration of mechanical ventilation in the intensive care unit. Anesthesiology. 2009;111:1308-16.

13. Gélinas $C$, Johnston C. Pain assessment in the critically ill ventilated adult: validation of the Critical-Care Pain Observation Tool and physiologic indicators. Clin J Pain. 2007:23:497-505.

14. Payen JF, Bru O, Bosson JL, Lagrasta A, Novel E, Deschaux I, et al. Assessing pain in critically ill sedated patients by using a behavioral pain scale. Crit Care Med. 2001;29:2258-63.

15. Barr J, Fraser GL, Puntillo K, Ely EW, Gélinas C, Dasta JF, et al. Clinical practice guidelines for the management of pain, agitation, and delirium in adult patients in the intensive care unit. Crit Care Med. 2013;41:278-80.
16. Egan TD, Lemmens HJ, Fiset P, Hermann DJ, Muir KT, Stanski DR, et al. The pharmacokinetics of the new short-acting opioid remifentanil (Gl87084B) in healthy adult male volunteers. Anesthesiology. 1993;79:881-92.

17. Minto CF, Schnider TW, Shafer SL. Pharmacokinetics and pharmacodynamics of remifentanil. II Model application Anesthesiology. 1997;86:24-33

18. Hoke JF, Shlugman D, Dershwitz M, Michałowski P, Malthouse-Dufore S, Connors PM, et al. Pharmacokinetics and pharmacodynamics of remifentanil in persons with renal failure compared with healthy volunteers. Anesthesiology. 1997;87:533-41

19. Dershwitz M, Hoke JF, Rosow CE, Michałowski P, Connors PM, Muir KT, et al. Pharmacokinetics and pharmacodynamics of remifentanil in volunteer subjects with severe liver disease. Anesthesiology. 1996;84:812-20.

20. Chalumeau-Lemoine L, Stoclin A, Billard V, Laplanche A, Raynard B, Blot F. Flexible fiberoptic bronchoscopy and remifentanil target-controlled infusion in ICU: a preliminary study. Intensive Care Med. 2013;39:53-8.

21. Rezaiguia-Delclaux S, Laverdure F, Kortchinsky T, Lemasle L, Imbert A, Stéphan F. Fiber optic bronchoscopy and remifentanil target-controlled infusion in critically ill patients with acute hypoxaemic respiratory failure: A descriptive study. Anaesth Crit Care Pain Med. 2017:36:273-7.

22. Sessler CN, Gosnell MS, Grap MJ, Brophy GM, O'Neal PV, Keane KA, et al. The Richmond Agitation-Sedation Scale: validity and reliability in adult intensive care unit patients. Am J Respir Crit Care Med. 2002;166:1338-44.

23. Chernik DA, Gillings D, Laine H, Hendler J, Silver JM, Davidson AB, et al. Validity and reliability of the Observer's Assessment of Alertness/Sedation Scale: study with intravenous midazolam. J Clin Psychopharmacol. 1990;10:244-51.

24. Puchner W, Egger P, Pühringer F, Löckinger A, Obwegeser J, Gombotz H. Evaluation of remifentanil as single drug for awake fiberoptic intubation. Acta Anaesthesiol Scand. 2002;46:350-4.

25. Gonzalez R, De-La-Rosa-Ramirez I, Maldonado-Hernandez A, DominguezCherit G. Should patients undergoing a bronchoscopy be sedated? Acta Anaesthesiol Scand. 2003:47:411-5.

26. von Elm E, Altman DG, Egger M, Pocock SJ, Gøtzsche PC, Vandenbroucke $J P$, et al. The Strengthening the Reporting of Observational Studies in Epidemiology (STROBE) statement: guidelines for reporting observational studies. Lancet. 2007;370:1453-7.

27. Albertini RE, Harrell JH, Kurihara N, Moser KM. Arterial hypoxemia induced by fiberoptic bronchoscopy. JAMA. 1974;230:1666-7.

28. Cracco C, Fartoukh M, Prodanovic H, Azoulay E, Chenivesse C, Lorut C, et al. Safety of performing fiberoptic bronchoscopy in critically ill hypoxemic patients with acute respiratory failure. Intensive Care Med. 2013;39:45-52.

29. Çoruh B, Tonelli MR, Park DR. Fentanyl-induced chest wall rigidity. Chest. 2013;143:1145-6.

30. Boom M, Niesters M, Sarton E, Aarts L, Smith TW, Dahan A. Non-analgesic effects of opioids: opioid-induced respiratory depression. Curr Pharm Des. 2012;18:5994-6004.

31. Del Blanco Narciso BB, Jimeno Fernandez C, Almendral Garrote J, Anadon Baselga MJ, Zaballos Garcia M. Effects of remifentanil on the cardiac conduction system. Our experience in the study of remifentanil electrophysiological properties. Curr Pharm Des. 2014;20:5489-96.

32. Zaballos M, Jimeno C, Almendral J, Atienza F, Patiño D, Valdes E, et al. Cardiac electrophysiological effects of remifentanil: study in a closed-chest porcine model. Br J Anaesth. 2009;103:191-8.

33. DeSouza G, Lewis MC, TerRiet MF. Severe bradycardia after remifentanil. Anesthesiology 1997;87:1019-20.

34. Poi PJ, Chuah SY, Srinivas P, Liam CK. Common fears of patients undergoing bronchoscopy. Eur Respir J. 1998;11:1147-9.

35. Lallo A, Billard V, Bourgain J-L. A comparison of propofol and remifentanil target-controlled infusions to facilitate fiberoptic nasotracheal intubation. Anesth Analg. 2009;108:852-7.

36. Rai MR, Parry TM, Dombrovskis A, Warner OJ. Remifentanil targetcontrolled infusion vs propofol target-controlled infusion for conscious sedation for awake fibreoptic intubation: a double-blinded randomized controlled trial. BJA: British Journal of Anaesthesia. 2008;100:125-30.

37. Soffler MI, Rose A, Hayes MM, Banzett R, Schwartzstein RM. Treatment of acute dyspnea with morphine to avert respiratory failure. Ann Am Thorac Soc. 2017;14:584-8. 
38. Banzett RB, Adams L, O'Donnell CR, Gilman SA, Lansing RW, Schwartzstein RM. Using laboratory models to test treatment. Am J Respir Crit Care Med. 2011;184:920-7.

39. Barnes H, McDonald J, Smallwood N, Manser R. Opioids for the palliation of refractory breathlessness in adults with advanced disease and terminal illness. Cochrane Database Syst Rev [Internet]. 2016 [cited 2021 Jan 30];2016. Available from: https://www.ncbi.nlm.nih.gov/pmc/articles/ PMC6485401/

40. Putinati S, Ballerin L, Corbetta L, Trevisani L, Potena A. Patient satisfaction with conscious sedation for bronchoscopy. Chest. 1999;115:1437-40.

41. Greig JH, Cooper SM, Kasimbazi HJN, Monie RDH, Fennerty AG, Watson B. sedation for fibre optic bronchoscopy. Resp Med. 1995;89:53-6.

42. Yıldırım F, Özkaya Ş, Yurdakul AS. Factors affecting patients' comfort during fiberoptic bronchoscopy and endobronchial ultrasound. J Pain Res. 2017;10:775-81.

43. Ryu JH, Lee SW, Lee JH, Lee EH, Do SH, Kim CS. Randomized double-blind study of remifentanil and dexmedetomidine for flexible bronchoscopy. $\mathrm{Br}$ J Anaesth. 2012;108:503-11.

44. Clouzeau B, Bui H-N, Guilhon E, Grenouillet-Delacre M, Leger MS, Saghi T, et al. Fiberoptic bronchoscopy under noninvasive ventilation and propofol target-controlled infusion in hypoxemic patients. Intensive Care Med. 2011;37:1969-75.

45. Bellolio MF, Gilani WI, Barrionuevo P, Murad MH, Erwin PJ, Anderson $\mathrm{JR}$, et al. Incidence of adverse events in adults undergoing procedural sedation in the emergency department: a systematic review and metaanalysis. Acad Emerg Med. 2016;23:119-34.

46. Schmidt M, Banzett RB, Raux M, Morélot-Panzini C, Dangers L, Similowski T, et al. Unrecognized suffering in the ICU: addressing dyspnea in mechanically ventilated patients. Intensive Care Med. 2014;40:1-10.

47. von Leupoldt A, Dahme B. Experimental comparison of dyspnea and pain. Behav Res Methods. 2007;39:137-43.

48. Beaussier M, Genty T, Lescot T, Aissou M. Influence of pain on postoperative ventilatory disturbances. Management and expected benefits. Ann Fr Anesth Reanim. 2014;33:484-6.

49. Du Rand IA, Blaikley J, Booton R, Chaudhuri N, Gupta V, Khalid S, et al. British Thoracic Society guideline for diagnostic flexible bronchoscopy in adults: accredited by NICE. Thorax. 2013;68(Suppl 1):i1-44.

50. Ni Y-L, Lo Y-L, Lin T-Y, Fang Y-F, Kuo H-P. Conscious sedation reduces patient discomfort and improves satisfaction in flexible bronchoscopy. Chang Gung Med J. 2010;33:443-52.

\section{Publisher's Note}

Springer Nature remains neutral with regard to jurisdictional claims in published maps and institutional affiliations.

\section{Submit your manuscript to a SpringerOpen ${ }^{\circ}$ journal and benefit from:}

- Convenient online submission

- Rigorous peer review

- Open access: articles freely available online

- High visibility within the field

- Retaining the copyright to your article

Submit your next manuscript at $\boldsymbol{\nabla}$ springeropen.com 